\title{
Corrigendum
}

\section{Corrigendum to "Early Growth Response Protein 1 Promotes Restenosis by Upregulating Intercellular Adhesion Molecule-1 in Vein Graft"}

\author{
Kui Zhang $\mathbb{D}^{1},{ }^{1}$ Jian Cao $\mathbb{D}^{1},{ }^{1}$ Ran Dong $\mathbb{D}^{1},{ }^{1}$ and Jie Du $\mathbb{D}^{2}$ \\ ${ }^{1}$ Cardiac Surgery, Beijing Institute of Heart, Lung and Blood Vessel Diseases, Beijing Anzhen Hospital Affiliated with Capital \\ Medical University, Beijing 100029, China \\ ${ }^{2}$ Vessel Biology, Beijing Institute of Heart, Lung and Blood Vessel Diseases, Beijing Anzhen Hospital Affiliated with Capital \\ Medical University, Beijing 100029, China
}

Correspondence should be addressed to Ran Dong; dongran6618@hotmail.com and Jie Du; jiedu@ccmu.edu.cn

Received 12 January 2021; Accepted 12 January 2021; Published 2 February 2021

Copyright (c) 2021 Kui Zhang et al. This is an open access article distributed under the Creative Commons Attribution License, which permits unrestricted use, distribution, and reproduction in any medium, provided the original work is properly cited.

In the article titled "Early Growth Response Protein 1 Promotes Restenosis by Upregulating Intercellular Adhesion Molecule-1 in Vein Graft" [1], there was an error in
Figure 4(c). The figure should show the internal control "GAPDH" blot. The corrected figure is shown below and is listed as Figure 4. 

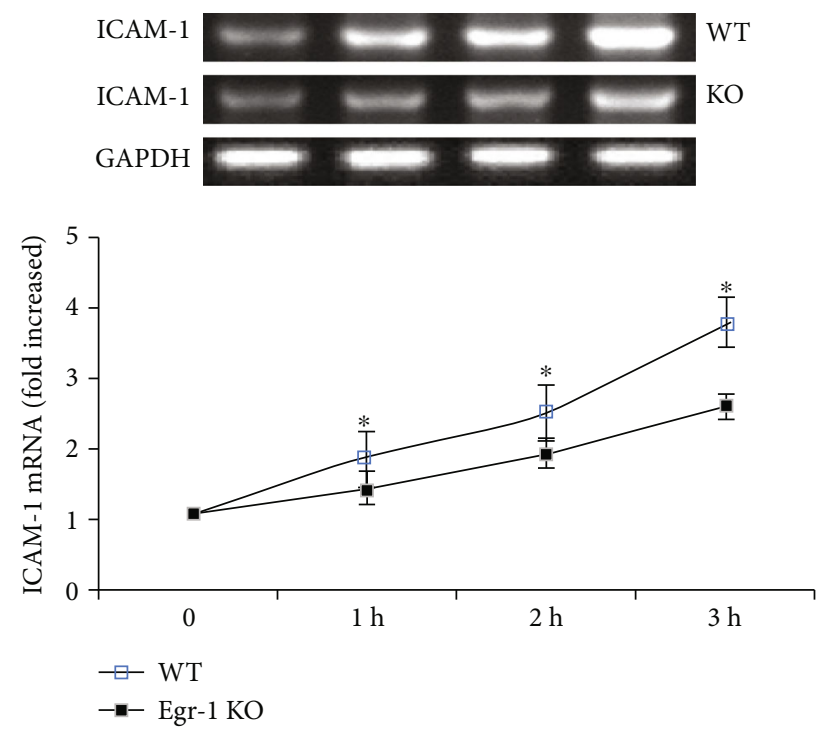

(a)

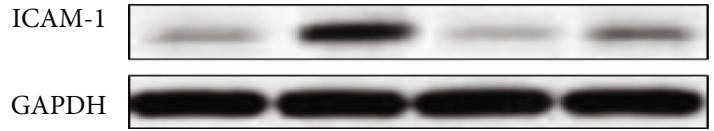

ICAM-1

GAPDH

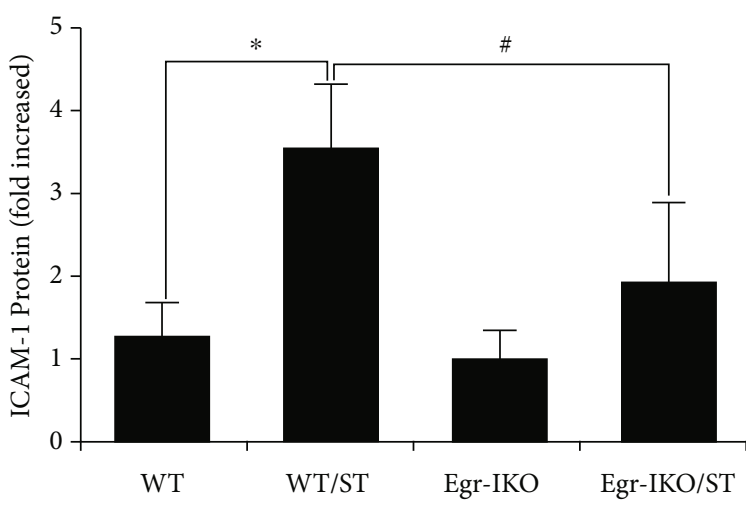

(b)



WT

Egr-1KO

Figure 4: Egr-1 knockout (KO) decreased ICAM-1 expression. (a) Venous ECs from WT and Egr-1 KO mice were isolated and stimulated with mechanical stretch from 0 to $3 \mathrm{~h}(n=5)$. ICAM-1 mRNA expression was determined by real-time RT-PCR. (b) Egr-1 KO decreased ICAM-1 protein levels after mechanical stretch stimulation for $24 \mathrm{~h}(n=5)$. Data are expressed as mean \pm SEM. $* P<0.05$ versus the WT group; ${ }^{\#} P<0.05$ versus the WT/ST group. (c) Egr-1 KO decreased ICAM-1 mRNA expression in the mouse vein graft model $(n=5)$. Data are expressed as mean \pm SEM. $* P<0.05$ versus the WT group. WT: wild-type mice; WT/ST: venous ECs from WT mice stimulated with mechanical stretch; Egr-1 KO: Egr-1 knockout mice; Egr-1 KO/ST: venous ECs from Egr-1 knockout mice stimulated with mechanical stretch.

\section{References}

[1] K. Zhang, J. Cao, R. Dong, and J. Du, "Early Growth Response Protein 1 Promotes Restenosis by Upregulating Intercellular Adhesion Molecule-1 in Vein Graft," Oxidative Medicine and Cellular Longevity, vol. 2013, Article ID 432409, 9 pages, 2013. 